\title{
Selective Oxidation: From a Still Immature Technology to the Roots of Catalysis Science
}

\author{
Robert Schlögl ${ }^{1}$
}

Published online: 18 August 2016

(c) The Author(s) 2016. This article is published with open access at Springerlink.com

\begin{abstract}
The design of heterogeneous selective oxidation catalysts based upon complex metal oxides is governed at present by a set of empirical rules known as "pillars of oxidation catalysis". They serve as practical guidelines for catalyst development and guide the reasoning about the catalyst role in the process. These rules are, however, not based upon atomistic concepts and thus preclude their immediate application in for example computer-aided search strategies. The present work extends the ideas of the pillar rules and develops the concept of considering a selective oxidation catalyst as enabler for the execution of a reaction network. The enabling function is controlled by mutual interactions between catalyst and reactants. The electronic structure of the catalyst is defined as a bulk semiconductor with a surface state arising form a terminating over layer being different from the structure of the bulk. These components that can be identified by in situ analytical methods form a chemical system with feedback loops, which is responsible for generating selectivity during execution of the reaction network. This concept is based upon physical observables and could allow for a design strategy based upon a kinetic description that combines the processes between reactants with the processes between catalyst and reactants. Such kinetics is not available at present. Few of the constants required are known but many of them are accessible to experimental determination with in situ techniques.
\end{abstract}

Robert Schlögl

acsek@fhi-berlin.mpg.de;

http://www.fhi-berlin.mpg.de/

1 Fritz-Haber-Institute der MPG, Faradayweg 4-6, 14195 Berlin, Germany
Keywords Alkane oxidation - Catalysis concepts - Metal oxide catalysts $\cdot$ System chemistry $\cdot$ In-situ analysis

\section{Introduction}

In the mid-1960s, at the Sohio Research Laboratories Cleveland, major advancements were made in the catalytic selective oxidation and ammoxidation of alkenes to produce material such as acrolein and acrylonitrile from propylene. One of the key investigators in this venture was R.K. Grasselli who, with his associates revolutionized the manufacture of chemical feedstock that are now a central feature of the modern polymer industry. An important series of papers described the oxidation and ammoxidation of propylene over bismuth molybdate catalysts, constituting a turning point in the industrial production of acrylic polymers [1-6]. These papers represented further a fundamental change in attitude towards the design of new solid catalysts: they acknowledged the importance of understanding the bulk structural properties of non-metallic solid catalysts. This seminal work extended the logic contained intrinsically in the significant earlier paper by Mars and van Krevelen [7, 8], who argued that in many selective oxidations of hydrocarbons it is not the atoms of gaseous oxygen that appear in the oxidized product, but rather the constitutional oxygen of the oxide sub-lattice in the solid catalyst. This concept was extensively deepened and filled with detail [9-12] by J. Haber. Recognizing the relevance of non-stoichiometry of the bismuth molybdate [13], and the ease of ionic migration resulting from it, initiated research to deliberately modify the composition of the many phases of bismuth molybdate that function as selective oxidation and ammoxidation catalysts (e.g., $\mathrm{Bi}_{2}$ $\mathrm{MoO}_{6}, \mathrm{Bi}_{2} \mathrm{Mo}_{3} \mathrm{O}_{9}, \mathrm{Bi}_{2} \mathrm{Mo}_{3} \mathrm{O}_{12}, \mathrm{Bi}_{6} \mathrm{Mo}_{9} \mathrm{O}_{15}$ ). In this way 
efficient and selective oxidation catalysts resulted from a conceptual insight. A combination of phenomena and techno-economic conditions prevented the repetition of such success stories in other important oxidation reactions that rest on catalyst systems (such as VPP or Mo-V mixed oxides) that are believed to follow the same general concept but brought to their present performance by multiple incremental improvements.

The relevance of bulk translational structures of catalysts in selective oxidation and the possible function of the lattice as reservoir for the critical reactant "active oxygen" form the basis of an assumed "speciality" of the class of selective oxidation catalysts in contrast to "normal" Langmuir-Hinshelwood reaction pathways. Assumed modes of operation in oxidation are different from the mode of operation of the standard model of heterogeneous catalysis implemented with the single crystal approach $[14,15]$. This concept is based upon rigid reconstructed active surface sites that are covered and uncovered by adsorption and desorption. The sites are connected with an infinite reservoir of free electrons from which redox equivalents can be lent and borrowed without any energetic "interest". The conceptual difference between standard and selective oxidation heterogeneous reaction modes created a barrier for research and largely confined the success of oxidation catalysis to empirical optimizations. These for practical applications successful afforts are paralleled by mechanistic hypotheses that are without a physical link to experiments or to the intricate structures of working catalyst systems. It is the purpose of this paper to show that the worlds of local static active sites and sites on oxidation catalysts are not different from one another and that the unifying concept of dynamical active sites can lead to a functional understanding of selective oxidation connected with physical concepts.

\section{The Empirical Conceptual Basis}

Selective oxidation of small organic molecules is not only a critical industrial practice but presents a considerable challenge for the science of catalysis. The reactions involve the simultaneous conduct of several types of chemical transformations and convert a stable starting molecule in a less stable product. Typical selective oxidation reactions for the C3 alkane are collected in Fig. 1. The reactions are ordered according to the number of water molecules being formed. The high stability of water presents a strong driving force for such reactions. It is thus obvious that a catalyst intended to produce a molecule with low initial driving force will require much higher constraints with respect to selectivity than a catalyst performing a reaction with much driving force. From this simple idea it is

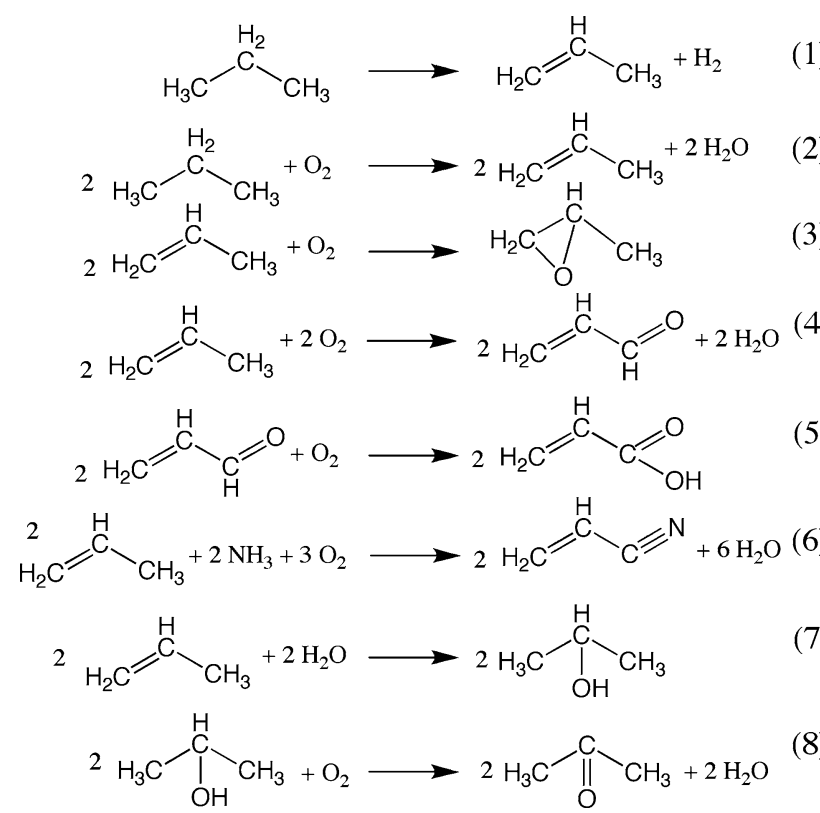

Fig. 1 Selection of reactions of propane involving selective oxidation. The important reaction path leading to $\mathrm{C}-\mathrm{C}$ activation and combustion is for simplicity not addressed here

obvious that the acrylonitrile synthesis [16] (6) should be the reaction to be performed relatively most facile in the collection of Fig. 1 and the dehydrogenation of propane (1) or the epoxidation of propene (3) should be the most challenging reactions.

Reactions $(7,8)$ in Fig. 1 indicate unwanted reactions of the primary product propene with water and consecutively with oxygen. Such processes are entry points to combustion or to the formation of unwanted side products. It is obvious that a demanding catalyst design is required to accelerate the wanted reactions such as $(4,5,6)$ but to simultaneously inhibit reactions $(7,8)$. A key to this control is the water management at the surface being controlled by acid-base properties from the catalyst side and by mass transport from the kinetic side. This aspect of selective oxidation is investigated [17, 18] but still incompletely understood.

From inspection of Fig. 1 it becomes intuitively clear that the regulation of the availability ("abundance") of active oxygen must be a key concern in devising a selective oxidation process.

The reactions in Fig. 1 are all formulated with the minimum stoichiometry supposing the participation of existing molecules. In many discussions in the literature the dissociation and activation of di-oxygen is omitted from the reaction leading to the formalism of $0.5 \mathrm{O}_{2}$ reactions. The activation of di-oxygen into redox equivalents acting selectively in $\mathrm{C}-\mathrm{H}$ activation and in addition of oxygen to the carbon backbone is a central issue of understanding selective oxidation. The whole concept of selective 
oxidation catalysts arouse from the desire to understand the properties of selectively acting oxygen. Formulating the reactions as seen in Fig. 1 gives a realistic estimate about the size of an active site having to store in generally accepted "single site" cyclic mechanisms within its boundaries all redox equivalents required for the reaction. If we assume that a metal centre can with low activation barrier change its oxidation state by one unit and if we deny the participation of anions as charge storage sites then we can deduce the number of metal atoms per isolated site from the stoichiometry given in Fig. 1. The reader may recognize the many conditions of this statement. This paper is about interrogating these conditions.

The central idea brought about by R.K. Grasselli and J. Haber was to use as reagent pre-activated oxygen existing in oxide systems. It was thought that the metal-oxygen bond strength would moderate the oxidising potential of oxygen atoms formulated as $\mathrm{O}^{2-}$ species. A catalysis concept was formulated in which the oxidising effect of „lattice oxygen“was used for creating oxidised molecules and in a separate step the oxide material should become replenished in oxygen using gas phase oxygen. In pioneering experiments of propene oxidation with copper oxide it was found [19] that a selectivity change occurred with ongoing depletion of lattice oxygen from highly unselective operation at high abundance of lattice oxygen to highly selective operation at lower abundance of lattice oxygen.

From these observations the design principle of all presently working selective oxidation catalysts was derived. It states that designing the structure of the active material can control the abundance of lattice oxygen and thus the selectivity of the process. The target was to limit the abundance of active oxygen to the stoichiometry requirement (equations in Fig. 1) of one turnover at one location of the reactive surface. No exchange of active oxygen between active sites should be allowed to suppress over-stoichiometric oxidation. This site isolation principle says that the active site must be designed such that the required abundance of lattice oxygen is part of its structure and that this structure must be chemically isolated from its neighbours such that no exchange of lattice oxygen between sites can occur. The concept says implicitly that the geometric structure of a reaction site must not collapse during exchange of active oxygen with the organic substrate and during regeneration from gas phase di-oxygen. Otherwise such an active site would not act catalytically and one would have to postulate that the formation of an active site from some precursor structure is part of the catalytic cycle. Such a dynamic view is not part of the generally accepted operation concept of heterogeneous selective oxidation. In most cases the observation of a very low reaction order in oxygen justifies the assumption that the generation of activated oxygen is not involved in the kinetically difficult step.

The site isolation was realized by constructing oxide structures such that "active centres" (open d-band elements) form no extended network of chemical bonds between each other but are interrupted in their mutual interaction by inactive sites (main group elements). This principle was brought to splendid operation with the series of Bi-molybdate catalysts used for propene selective oxidation and with the vanadyl pyrophosphate system [20-25] for butane selective oxidation. The site isolation concept is ever since the most powerful design rule for oxidation catalysts.

The concept is illustrated in Fig. 2 with uranium antimonide following the published strategy [6, 26, 27] of R.K. Grasselli. Two structural variants $\mathrm{USbO}_{5}$ and $\mathrm{USb}_{3} \mathrm{O}_{10}$ exist that can interconvert. Good arguments exist for the formal identical oxidation state of +5 for both cationic species rendering strong covalency in their respective
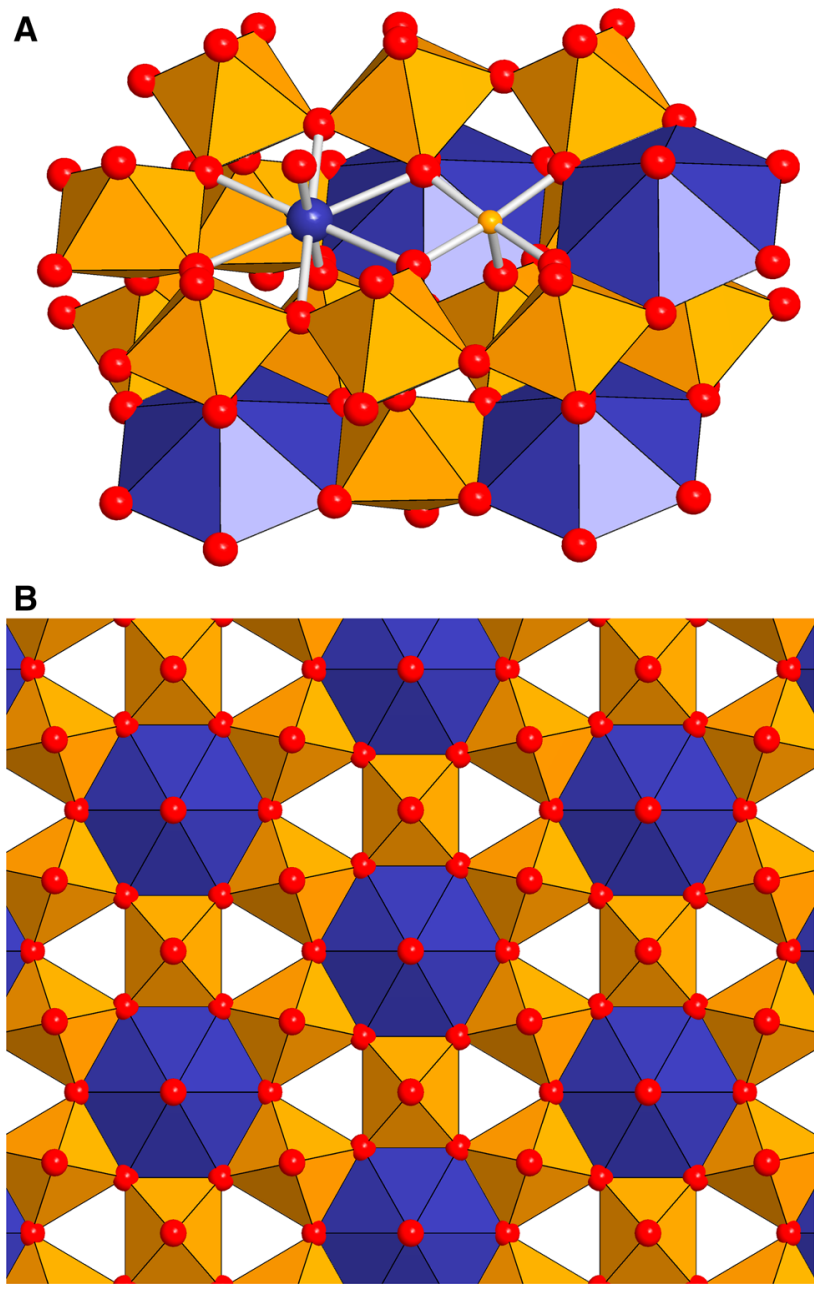

Fig. 2 The $\mathrm{USb}_{3} \mathrm{O}_{10}$ phase as example for site isolation. Model a shows the active site as constructed by Grasselli [26]. Model b shows the structure in $\mathbf{a}, \mathbf{b}$ projection 
bonding the dominating mechanism of interaction; this should give rise to good site isolation as the mobility of redox equivalents will be limited. The models in Fig. 2 depict the active site as assumed by Grasselli et al. in two projections. One can well see that according to the site isolation concept all open-d shell ions are isolated from each other. The reaction of interest (Eq. 6 in Fig. 1) requires the exchange of six electrons and hence clearly of more electrons than one redox-active site shown in Fig. 2a can accomodate. A suitable ensemble size would be the feature depicted in Fig. $2 \mathrm{~b}$ with $6+1$ redox-active centres isolated from each other and from the surrounding by antimony-oxo octahedral that should be redox-inactive at the conditions of selective oxidation.

We will discuss later that metal oxide systems are not only arrangements of hypothetical "molecules" but they form extensive band structures in which electrons are shared between atoms rendering the idea of geometric site isolation a rather formal concept. This argument makes it clear that site isolation requires more than the geometric separation of open-d state centres from each other. The existence of defects in the surface termination idealized by a cut through the bulk translational structure discriminating small ensembles of the translational symmetric motifs such as shown in Fig. 2 destroys the translational symmetry of the surface in lateral directions and thus can provide a way to physical site isolation. Defects or at larger scale "metastable phases" are thus an essential part of working catalysts explaining the strong relation between catalytic performance and the kinetic details of catalyst synthesis. This was summarized in other words by E. Bordes with her concept [28] of "surface nanodomains" existing for stability reasons in close similarity to the underlying structure. It is more realistic to state that a complex oxide may terminate in its catalytically active form in clusters (or rafts) of the transition metal component separated from each other by a network of oxide polyhedra made from the main group element. This ensemble is supported on its parent oxide system that provides not only the atom reservoir for the formation of this termination motif but also acts as heat transport medium. We will discuss below that the bulk further acts as control system for the electronic structure of the terminating phase with respect to the molecular levels of the adsorbed reactants.

The function of "material storage" of the bulk phase explains the necessity to invoke mobility of oxygen as the likely originator of defects in oxide systems. This function is independent from the proposed function as selective reagent, which the author suggests to be not essential under conditions of simultaneous presence of oxygen and hydrocarbon. Without the real structure of the bulk (sum of translational and defect structure) providing soft spots in the lattice and the possibility of self-diffusion of oxygen providing the driving force for atom displacements in a crystalline solid far below its melting point, it would be poorly possible to reconstruct the surface of a crystalline solid with multiple bonds in all directions of space. Hence the phenomenological correlation between lattice oxygen mobility and selective catalytic action finds a structural interpretation, as the oxygen mobility indicates and supports the creation of surface nanodomains that contain the actives sites. This view is supported as explanation of a series of instructive experiments [29] in which the dispersion of a Bi-Mo catalyst for propene oxidation was varied by several methods: it was found that dispersed forms with strong support interactions act only unselective whereas selective oxidation required a bulk phase capable of bringing about a termination layer of nanodomains. This was however not the interpretation of the authors who rather invoked the direct function of lattice oxygen for rationalizing their results.

In Fig. 3 a practical example is given of the termination of a highly stable complex oxide catalyst namely the M1 catalyst used for propane oxidation. The crystal structure scheme in Fig. 3a can be seen in the experimental image (Fig. 3b) of a thin slice of the catalyst exhibiting the same orientation as assumed for the scheme. Despite prolonged operation at $673 \mathrm{~K}$ in the demanding atmosphere of propane oxidation the lattice of the catalyst is still to a large extent in translational order. The depth to which the termination structure [30] with nanodomains disturbs the symmetry is smaller than the thickness of one unit cell. In this outer region multiple forms of interconnections between polyhedra can be seen that are hard to detect by most conventional analytical methods.

Application of the site isolation concept requires the predictability of the structure of active sites. In complex oxides it is assumed [31] that active sites are motifs or parts thereof of the crystallographic structure of the oxide. Even if the relevant surface domains are not elements of this translational structure as exemplified in Fig. 3, its knowledge is key to identify these domains that should be rather similar to the parent structure for reasons of structural stability. The details of the bulk crystal structure would thus matter as they contain encoded the possible function of actives sites in catalysis. This postulate renders the precise structure determination of the oxide phase in question into a decisive [32-39] experiment. It is noted here that with the increasing precision of structured determination [40] not only intergrowth of minority phases that cannot be seen easily with diffraction methods but also local dynamics at interconnection sites of polyhedra supporting the notion of surface reconstruction in termination phases have been observed [41, 42] experimentally.

As the catalytic performance of the complex oxide systems increased, a series of additional concepts were 

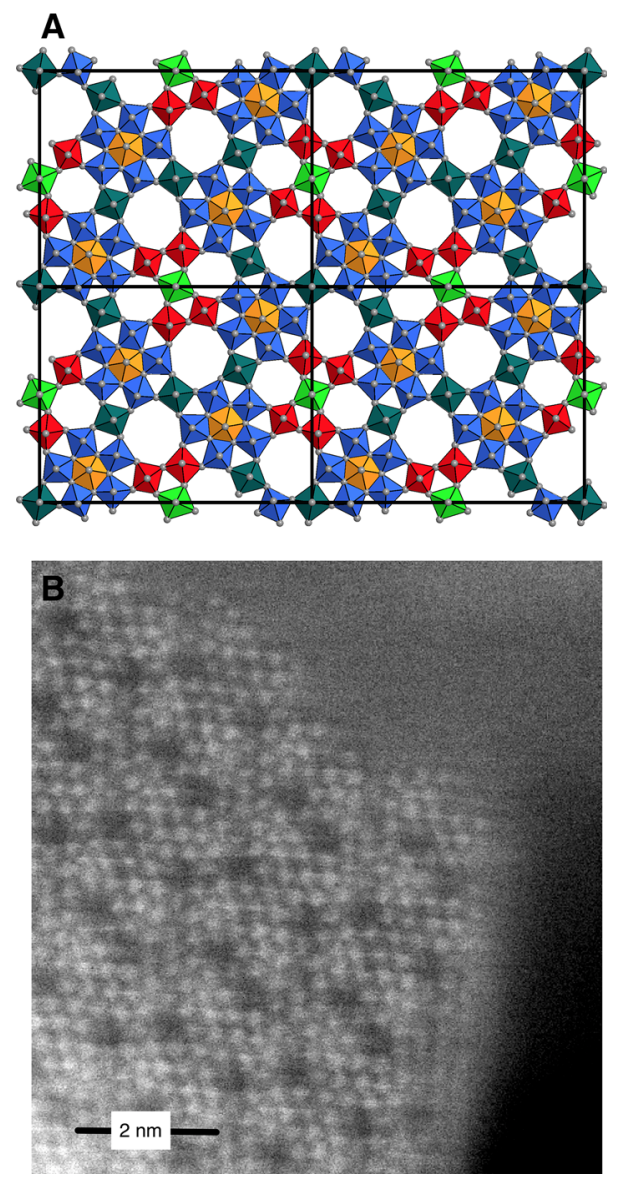

Fig. 3 a Projection of the crystal structure of the M1 phase onto the (001) plane. One can see the characteristic channel structure housing the Te component. The colour code indicates the in-equivalent sites of the structure and not the atom type occupation. b shows a HAADSTEM image of a thin slice of a M1 catalyst after use in propane oxidation. One can see the retention of translational symmetry until almost the outer surface where the connectivity of the metal oxide polyhedra ("spots" in the image) gets randomized. Clusters of pentagonal units and rafts of polyhedra can be seen forming likely the nanodomains discussed in the text

developed to refine the understanding based upon the core concepts of lattice oxygen function and site isolation. Table 1 summarizes these concepts in a modern formulation given [19] by R.K. Grasselli in 2002 in the original sequence of the author.
The table comprises both the operation conditions and the chemistry of the catalytic material. Both are of concern when ordering our empirical knowledge into such heuristic concepts. It is noted that these concepts are without a rigorous grounding in physical properties of the system, which is not uncommon with phenomenological concepts in chemistry. They cannot be deduced form first principles of chemical bonding. For this reason it can be understood that some of these concepts are not independent from each other as they refer to chemical phenomena of the same physical origin. This is indicated in the last column of Table 1.

With these concepts the evolution of several generations of complex oxide systems [19] was guided for the improved synthesis of acrylonitrile. The example of a highly productive acrylonitrile synthesis catalyst $[43,44]$ with the composition:

$$
(\mathrm{K}, \mathrm{Cs})_{\mathrm{a}}(\mathrm{Ni}, \mathrm{Mg}, \mathrm{Mn})_{7.5}(\mathrm{Fe}, \mathrm{Cr})_{2.3} \mathrm{Bi}_{0.5} \mathrm{Mo}_{12} \mathrm{O}_{\mathrm{x}} / \mathrm{SiO}_{2}
$$

sheds light on the level of sophistication reached by the Grasselli group in the application of individual concepts from Table 1 . The catalyst further serves as example for the idea $[28,45,46]$ of phase cooperation. It is argued that an alpha Bi-molybdate cooperates with a beta Fe-molybdate phase in such a way that the alpha phase performs the organic chemistry and the beta phase replenishes the lattice oxygen of the alpha phase. Such co-operation should be facilitated through structural similarity of the phases and common redox-active elements such as Fe [47].

The generalisation of using a bulk structural motif as lead for searching the phase space of complex oxides for performance catalysts is, unfortunately, not universally valid as was documented recently [48] in the case of butane oxidation. It is re-assuring that the physical method of determining in situ the charge carrier dynamics provided the insight $[49,50]$ why the structures synthesized were unable to perform well as catalyst. The optimization of the M1 catalyst was frequently the subject $[51,52]$ of combinatorial searches. The design of libraries was initiated using the concepts of Table 1. Substantial improvements were reported [53] by using purely statistical concepts rather than chemical insight. The future will show if such
Table 1 Concepts denoted as"pillars" of how to design selective oxidation catalysts according to R.K. Grasselli

\begin{tabular}{llll}
\hline Concept No. & Designation & Describes & Dependent on concept no \\
\hline 1 & Lattice oxygen & Process & Independent \\
2 & Strength of metal-oxygen bond & Catalyst & $1,3,4$ \\
3 & Motif of host structure & Catalyst & $1,2,4,6$ \\
4 & Redox properties of cations & Catalyst & $1,2,3$ \\
5 & Multifunctionality of active site & Process & Independent \\
6 & Site isolation & Catalyst & Independent \\
7 & Phase cooperation & Catalyst & Independent \\
\hline
\end{tabular}


approaches will be generally successful that ignore the need for functional understanding of a system for catalytic application.

A particular strength of the concepts in Table 1 is that they address together not only the process chemistry of selective oxidation but also the material science part of it. In other words, these concepts link material properties to process conditions. In this way they are so valuable to practical development work as they give guidelines to search for certain structures and to define suitable operation conditions for a given material. Concepts nr 1 and 5 dictate the chemical potential range in which a catalyst can be operated: the oxygen potential must be kept such as that the oxide lattice stays under-stoichiometric with respect to the hypothetical stoichiometry for the sum of the highest valences of all cations. As the chemical composition of the reactant phase is quite complex it is not easy to fulfil these rules by design. The oxygen potential from the gas phase is strongly moderated by the simultaneous presence of reducing organic species and by water vapour that is either added or results from selective and unselective oxidation of hydrocarbon molecules. The concepts allow, however, to experimentally probing the range of useful reactant mixtures. The range of selective stoichiometric reactions is found first using gas feeds without oxygen and consecutively the loss of lattice oxygen is determined through back-titration with gas phase oxygen. This procedure was described in early works [54] and is still a powerful means of determining operating parameter spaces.

The concepts 2, 3, 4 can be summarized into one concept of selecting the best electronic structure. The respective concepts follow from each other as bulk structural motifs, covalence of metal-oxygen bonds and structural motifs are all consequences of the combined local and extended electronic structure enabling redox properties and defect dynamics [49, 55-57] at fixed chemical potentials. The operation of a selective oxidation catalyst can be described in the framework of the thermodynamics and kinetics of oxygen anion [58-61] conductors. As the chemical potential of the reactants is quite well fixed by explosion boundaries of alkane-oxygen mixtures and the redox potential of the maximum attainable partial pressures of products, the range of the periodic table is rather limited where suitably stable oxides with dynamical properties can be found. It is pointed out that this limitation is coupled to the condition of using gas phase di-oxygen as oxidant; in many organic synthetic oxidations more activated oxidation agents are used with the consequence that the range of suitable elements gets much wider.

In a review on ammoxidation $[62,63]$ the "Bermuda" phase triangle of selective oxidation is described. The open $\mathrm{d}$-shell elements $\mathrm{V}, \mathrm{Nb}$, Mo forming the triangle are combined with $\mathrm{Te}, \mathrm{Sb}$ (and $\mathrm{P}$ ). This limited range of key elements [36, 43, 64-67] is augmented by a large number of dopant elements added under phenomenological guidance and supported by high throughput experimentation $[53,68]$ following the concepts $1-5,7$ from Table 1 . The enormous complexity of modifications occurring by adding these dopants, makes is hard to rigorously prove the validity of the empirical concepts even when the addition of dopants is beneficial for catalysis. The key elements alone allow however, already for a large number of crystal structures exhibiting each a significant variation in metaloxygen bonding geometries and hence electronic structures. These structures are characterized by non-dense packing motifs following the substantial covalence of metal oxygen bonds leading to orbital control of the bonding situation rather than to charge control as for ionic compounds. The structural variability gets enormously much larger if one considers ordered defect variants of the parent structural motifs. Amongst those the oxygen anion defect mechanism by changing the connectivity of two adjacent metal-oxygen polyhedra by a small con rotation or dis-rotation leading to a transformation of a chain into a di-block [12] structure is the most important one. Ordered forms of this defects cause shear structures [69-78] to evolve, that were detected in many complex oxides.

The concept of lattice oxygen as source for selective atomic oxygen is central to most interpretations of selective oxidation reactions. In its unrestricted form $[19,79-81]$ the concept calls for free mobility of the resulting lattice defect throughout the catalyst. If this would be correct then it is hard to understand how supported or even grafted catalysts exhibiting only 2-dimensional rafts of active oxide would perform well as selective oxidation catalysts. This argument is only partly valid as low-dimensional oxide systems function well in oxidative dehydrogenation reactions but are unable to perform selective transfer of oxygen species: unfortunately they are quite active in unselective combustion of pre-activated reagents. This general deficit may find its explanation not so much in the action of lattice oxygen but rather in the lack of control of oxygen activation through the absence of coupling of the surface electronic structure with that of the bulk as discussed below. All this is in agreement with the experiments described above [29] and with many related observations [82-89].

If the lattice defects and the related redox equivalents would move unrestricted (with activation energies below that of the catalytic transformation) in the solid catalyst, one expects ionic conductivity and semiconducting electronic properties that are indeed detected for performance catalysts such as VPP or M1 [50, 56]. Consequently, the site isolation would break down as more active oxygen could be generated from available electrons at the surface than required for selective oxidation and the catalyst would eventually become chemically reduced and hence de- 
activated. All this happens if one reacts performance catalysts with pure hydrocarbons. Under catalytic steady state conditions the activation of oxygen must be restricted by a limiting factor in order to allow continuous selective oxidation.

It is suggested to define the concept of lattice oxygen in the following way. The availability of lattice oxygen and their redox equivalents for catalytic reactions should be restricted to the active site. Site isolation means then the formation of chemically effective boundaries for the oxygen mobility in the rest of the oxide system. An active site is considered as a cluster of atoms representing one independently acting site performing the whole conversion of the substrate and the regeneration of the site. The postulate that active lattice oxygen should come out of subsurface or bulk layers should be removed. I. Wachs [88, 90, 91] suggested such a definition with the introduction of the term "surface lattice oxygen". Its circumstantial evidence coming from isotope exchange kinetic arguments [92] are not yet compelling in absence of proof that surface isotope exchange processes are intrinsically faster than their bulk counterparts.

Such a more specific definition of lattice oxygen and site isolation holds only for the case of concomitant presence of oxygen and reactants in the gas phase of an oxide catalyst (termed "catalytic mode"). The same oxide system can exhibit quite different active sites when it is operated in the way of space-time separated reactions with organic substrate and oxygen gas (termed "stoichiometric mode"). It is noted here that these two modes operate on different properties of the catalyst caused by the participation of the oxide bulk with its transport mechanisms in the latter case and the restriction of the redox transport to the surface or eventually sub-surface region in the former case. In the scientific discussion these differences were not always sufficiently separated although in the original work of the SOHIO group this distinction is clearly made. The extrapolation of valid observations made in the stoichiometric mode [93] (responses of the catalyst to pulses of reactants or oxygen) to the mode of operation in the catalytic mode must be regarded with reservation as different material properties of the same system are involved.

Experiments of the Grasselli group on M1 with pulses of propane/ammonia [94] to study lattice oxygen in ammoxidation reveal the transition from the action of a combination of nucleophilic and electrophilic oxygen in a catalytic surface layer leading to the formation of acrylic acid, $\mathrm{CO}_{\mathrm{x}}$ and acrylonitrile into a stoichiometric operation where deeper lattice oxygen (estimated 70 monolayers subsurface) gives only rise to the action of nucleophilic oxygen resulting in propene and acrylonitrile at low overall conversion. The experiment confirms that the reactivity of active sites responds to the oxygen chemical potential. The abrupt transition further indicates that the nature of the active sites changes: oxygen species that transfer onto organic substrates seem to be stored only at the surface and cannot be replaced by bulk lattice oxygen diffusion from sub-surface layers. The observation is in line with the notion that a surface termination layer is created in steady state operation and is different in catalytic action from the bulk termination prevailing under stoichiometric operation conditions.

\section{Towards a Physical Basis of Selective Oxidation}

The clearly non-exhaustive discussion of the scientific content of the concepts collected in Table 1 reveals their validity in the sense of providing guidance in selecting combinations of catalytic materials and their operation conditions for selective oxidation reactions. The lack of causal and quantitative structure-function relations prevents however the application of these concepts as predictive tool or as basis for the often desired "design" of catalytic material. As with the ever-increasing challenges of the raw material change in chemical industry the need for at least knowing the limits of oxidation reactions in terms of selectivity and productivity becomes more and more urgent, it is suggested to evolve the existing conceptual basis into a state where a link to physical concepts can be made and knowledge-based experimentation can be performed.

This evolution includes the following steps that are partly executed in present research. It was, however not yet possible to focus the research efforts to any particular system in such a way that all elements were executed. We thus still have incomplete knowledge about the function and performance potentials of all selective oxidation reactions. This may explain the reluctance to move forward with novel process implementations making use of lower alkanes as feedstock for large-scale chemical transformations. The following enumeration of essential development steps may still be incomplete, as their effectiveness in meeting the challenge of unsatisfactory oxidation reactions could not be demonstrated as yet. The discussion is confined to the activation of small and not functionalized substrates with molecular oxygen and may not apply strictly to the oxidation of activated structures and the use of more reactive oxidants.

1. Consider selective oxidations as networks of processes following from activating a non-reactive molecule.

2. Construct the network with sufficient detail to describe groups of elementary steps associated with $\mathrm{C}-\mathrm{H}$ activation, $\mathrm{C}-\mathrm{O}$ insertion and $\mathrm{C}-\mathrm{C}$ cleavage; avoid using physically not existing reagents $\left(0.5 \mathrm{O}_{2}\right)$. 
3. The resulting sequence of consecutive reactions with multiple intermediates may require more than one site; allow for sufficient specificity of active centres that a chemically plausible selectivity can be expected.

4. Macro-kinetic observations form no suitable basis for deriving mechanistic considerations; beware of temptations of over-simplifications. This applies for example to the details of the activation of molecular oxygen as well as to the multiple effects of acid-base functions on a redox catalyst

5. Observe the catalytic function of a material in a wide range of operational conditions. The dynamical feedback of chemical potential and active phase calls for a specific optimum of each catalyst with respect to its operation conditions. The practice to vary the catalyst chemistry and test with fixed conditions is not helpful for elucidating function and potential of a catalyst. It is mandatory to observe the limitations of transport of mass and energy and to study deviations of the generally assumed mean field approximations.

6. Active sites may not be static; allow structural dynamics for formation of such sites; include the kinetics of active site formation in the overall kinetic model. Practically this means that careful measures may be needed to activate the catalyst after synthesizing its precursor.

7. Obtain the necessary chemical observations of the catalyst under working conditions. This applies to the bulk structure as much as to the surface termination. In-situ functional analysis is essential for deriving knowledge about the constitution of a working catalyst. No shortcuts in conditions and materials can be taken.

8. If models are used for elucidation of the active structure, ensure that the models perform the overall oxidation reaction of interest; no proxis are possible due to the complex interplay of catalyst structure and chemical potential of reactants.

9. Understand the chemistry of the synthesis of a catalyst in the same detail as the catalytic process of interest. Catalysts are non-equilibrium functional materials. Be ready to assume that the catalytic function is a transient property of the catalyst structure on its way to thermodynamic equilibrium. Kinetic aspects of catalyst formation and activation are thus decisive in controlling structure and lifetime of the active phase.

10. Attempt to cross-link experimental observations and model assumptions with theoretical input. Theory can deliver detailed insight into molecular mechanisms rationalized with experimental observations provided they are made under strictly known boundary conditions. Theory may become predictive for material properties of working catalysts, at least in excluding non-functional material options.

Multiple aspects of executing these steps in the selective oxidation of propane can be found for example in a review article [95] providing support for the concept of a dynamical catalyst structure. Unfortunately, even for this well-studied reaction sequence $[52,55,67,96]$ and the existence of stable and phase-pure catalysts [40-42, 55, 96-98] the advocated understanding is not reached as the steps enumerated above are only executed in a fragmented way. Here, two aspects of this work will be presented in detail. A reaction network suitable for deriving a kinetic model is presented. A concept is discussed for the interplay of the surface termination layer and the bulk semiconductor of the M1 catalyst in self-limiting the activation of oxygen. These aspects are two elements in the envisaged functional understanding of propane oxidation that is based upon physical concepts. The reader may notice that these elements could equally well serve as support for the concept list presented in Table 1 and that they are not in contradiction to any of the statements made there. They do illustrate, however how the steps towards evolution of the empirical concepts into a physics-based concept may be put into practice.

\section{A Reaction Network}

Figure 4 shows the layout of the reaction network following from the activation of propane over a bulk catalyst such as M1 or VPP in the presence of oxygen and water. Experiments from our group [96, 99, 100] and a discussion of literature results supporting that network are collected in a book [101].

The Figure shows clearly that a whole basket of reaction products is possible. The abundance of water in the feed and the residence time at the catalyst are key parameters to decide between propene formation (dry, fast) and acrylic acid production (slow wet). Many catalysts perform only the oxidative dehydrogenation with minute selectivity to acrylic acid. The experimentally verified separation [96] of propene formation, acrylic acid formation and combustion requiring multiple steps [102] of $\mathrm{C}-\mathrm{H}$ activation, $\mathrm{C}-\mathrm{O}$ formation and deoxygenation indicates that more than one site may have to cooperate for the whole reaction sequence. It is instructive to transform Fig. 4 into an abstract form of a network giving the possibility to illustrate the co-operation of the different elementary reactions enumerated above. This is illustrated in Fig. 5. 


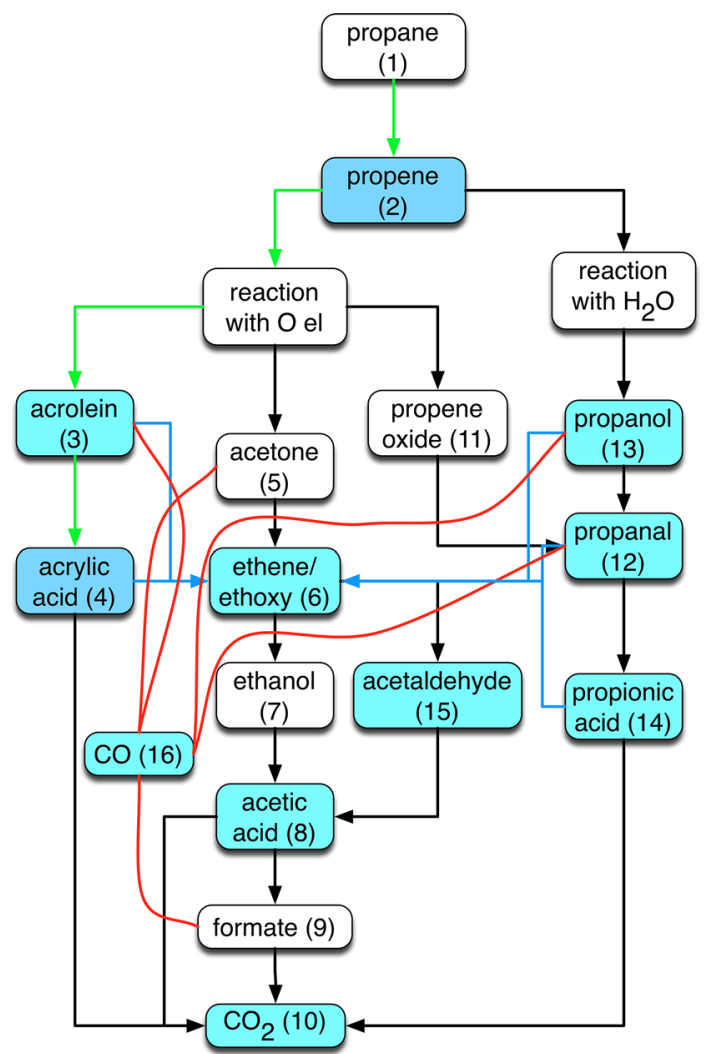

Fig. 4 Reaction network of propane activation. All blue species can be found as main components or traces in reaction products. Their abundance depends on the combination of catalyst and reaction conditions. The green arrows indicate the desired reaction to acrylic acid. Other connectors are coloured for clarity only

From this Figure we see that the straight reaction channel of the desired reaction branches out in several classes of parallel and consecutive reactions. The critical step for this is the reactivity of propene with either electrophilic oxygen or water. One may notice further the central role of ethene or ethoxy on the pathway to total combustion. We exclude in this still simplified scheme all radical reactions. We omit also many dehydrogenation steps requiring nucleophilic oxygen and producing $\mathrm{OH}$ for which the acid-base properties of the catalyst are relevant. The suppression of this topic follows from reasons of simplicity on the one side and from the experimental observation that under performance conditions with or without deliberate steam addition the reactive surface seems to be equilibrated with $-\mathrm{OH}$ functions. This view is experimentally not yet fully verified [103-108] and deserves substantial additional effort as well as the functional disentanglement [109] of Broensted acidity and Lewis acidity on reactive oxide surfaces.

We also see that several elementary reactions co-operate to achieve a desired transformation. This fulfils the above quoted concept of multifunctionality (Table 1) but

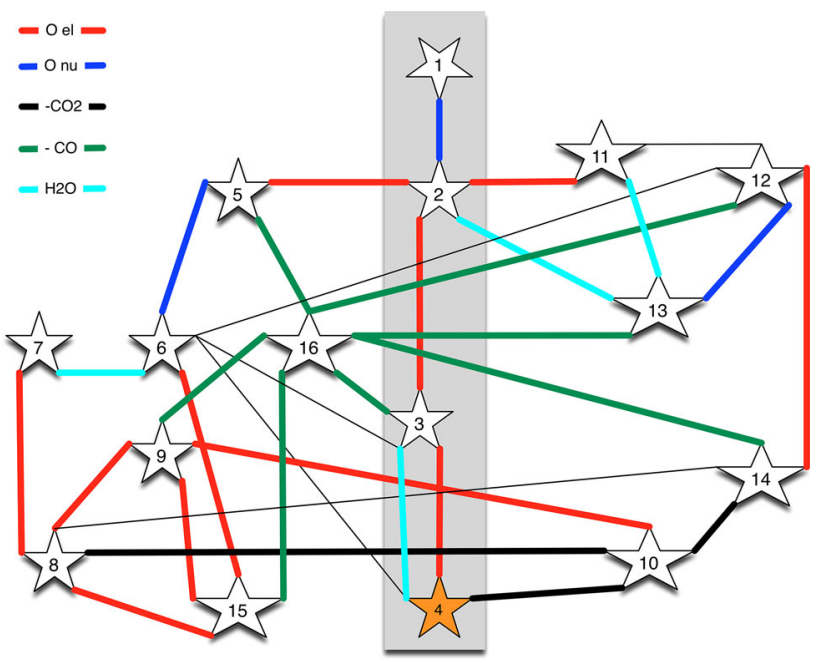

Fig. 5 Topological representation of the reaction network from Fig. 4. The nodes are denoted with the numbering scheme from Fig. 4. Node 4 represents acrylic acid as desired product. The coloured lines encode elementary reactions defined as processes that perform one chemical transformation of a substrate. The shaded area denotes the desired reaction pathway. The thin lines indicate major intramolecular rearrangements. The reactions correcting the hydrogen stoichiometry are largely omitted for clarity. This leaves the incorrect impression that the nucleophilic (basic) sites may be less relevant than electrophilic (oxidizing) sites

highlights the difficulty of creating selective overall reactions. One further recognizes the multiple reaction pathways to $\mathrm{CO}$. The ratio $\mathrm{CO} / \mathrm{CO}_{2}$ could be an instructive indicator for the relevant reaction pathways provided that no other sources or sinks for CO exist. Such a sink would be the water gas shift reaction as well as the reverse reaction would consume $\mathrm{CO}_{2}$. The likely to be expected oxidation of $\mathrm{CO}$ to $\mathrm{CO}_{2}$ is a difficult reaction $[96,100]$ on selective oxidation catalysts with high performance. This explains the initially disturbing observation that an oxidation catalyst that is capable of activating an alkane leaves $\mathrm{CO}$ untouched. Figure 5 illustrates further the challenge of constructing selectivity into a process arising from the multitude of reaction pathways observed, once an alkane molecule is activated to an olefin. The multiple role of water is again obvious. As much as it may be needed to generate free acrylic acid as much it drives the intermediate propene into combustion when it initiates its decomposition by forming an alcohol.

From the intricacy of Fig. 5 one may have doubts that a single type of site can achieve all this and one wonders how a desired product would ever make it away from the catalyst surface when seeing all the many reaction possibilities. In order to make this indeed chemically plausible beyond the hint towards the elevated reaction (desorption) temperature facilitiating rapid transport, the author puts forward the idea of modifying the concept of phase cooperation into a concept of site cooperation without having to 
make an explicit assignment of reactive sites to crystallographic phases which may be difficult in considering the arguments put forward with the discussion of Fig. 2. If we go along with this idea then we may sort the intricacy of Fig. 5 in four different sites performing the assumed initial reaction in sequences leading to desired or undesired products with high specificity. Figure 6 describes these sites as segments from the network displayed in Fig. 5.

We recognize that we need four different sites performing nucleophilic $\mathrm{C}-\mathrm{H}$ activation (site 1), electrophilic oxygen transfer (site 2), the hydration of double bonds (site 3 ) and the decarbonylation reaction (site 4) as their ratecontrolling process. Only site 1 and 2 perform one single elementary reaction to achieve their transformations. The other 2 sites need multifunctionality. It may thus be concluded that the details of sticking of reactants decide over the character of a site and that not 4 local geometries but merely 2 sites may co-exist that are tuned to their reactivity by a combination of the chemisorbed species with the overall electronic structure of the surface that in turn is controlled by the local chemical potential of the surrounding atmosphere. This is compatible with a theoretical analysis [102] of the reaction network of propene oxidation suggesting that vanadium-peroxo species resulting from partial activation of oxygen on reduced vanadia sites are the key controlling factor. The feedback topology of the reaction network connecting catalyst chemistry with reactant structure precludes attempts of finding and counting active sites by single probe molecule reactions at arbitrary chemical potential. Also the current practice of characterizing intermediates by dosing them onto the catalyst and observe their reactivity is not adequate as long as the chemical potential of the intermediate does not match that of the standard reaction atmosphere.

From inspection of Fig. 6 one may deduce that the quest for total selectivity in oxidation catalysis may be a bold target. Reactive catalysts with high productivity will most likely open up all reaction channels indicated in Fig. 6. Optimization of transport kinetics and short contacts of reaction products exhibiting high chemical potential with the reactive catalyst would be desires. Both mesosopic properties of the reaction system are only crudely realized in so-called plug flow reactors. It may thus well be that we need advanced reactor concepts and/or compositional profiles in reactor beds in order to improve the performance of oxidation processes. To rely on the material chemistry of catalyst design alone may be an insufficient measure in attempts to overall boost the performance of oxidation reactions. The mesoscopic properties form a second feedback system between catalyst chemistry and reaction performance including the details of the reactor apparatus and of the macroscopic catalyst properties (shapes, pores, thermal and charge carrier transport).

One possibility to explore this conjecture may be the construction of multiscale kinetic models [110] using the site cooperation approach as indicated in Fig. 6. One may attempt to define the parameters of each of the reaction chains shown in Fig. 6 independently and then create a meta model with parameters for each reaction chain. From there on one may theoretically model the molecular site requirements, optimize computationally their performance and detect the overall most critical reaction step. This
Fig. 6 Separation of the network from Fig. 5 into individual functions (sites) of the respective first reaction step. The numbering scheme and the colour code are the same as in Fig. 5

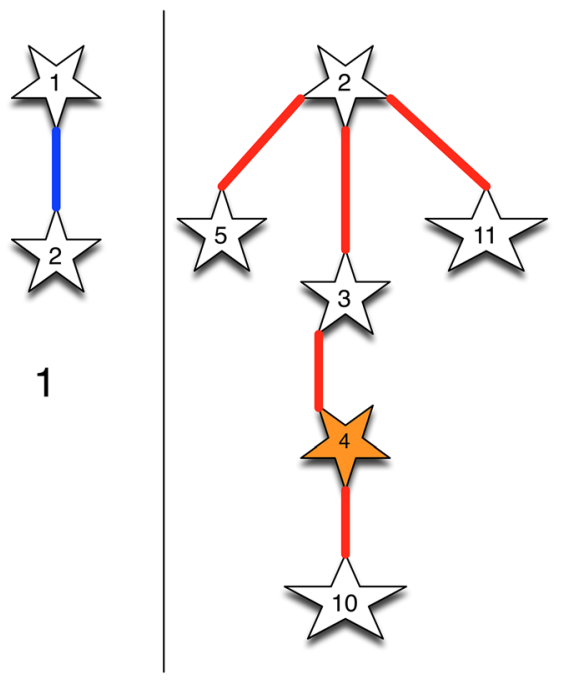

2

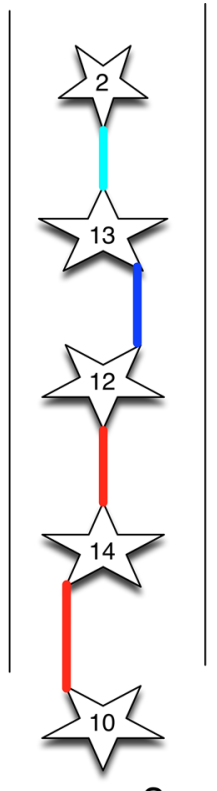

3

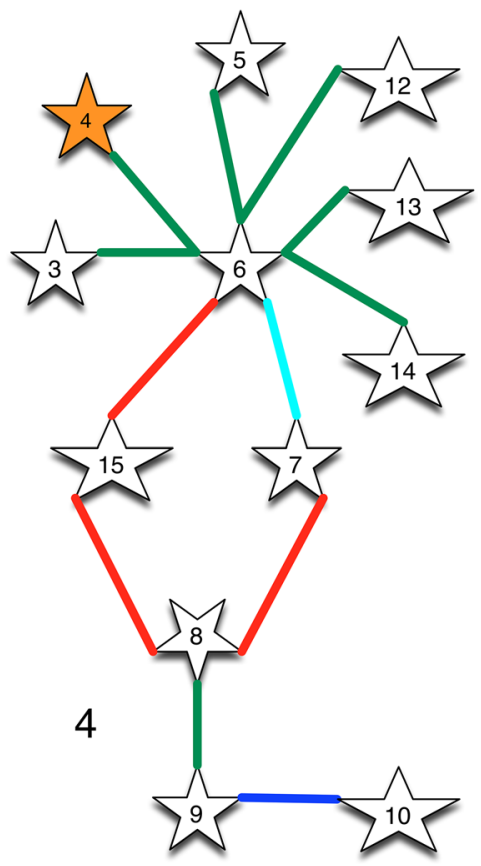


exercise must include the dynamics of active sites explicitly: we see that selective oxidation catalysts terminate [92, 111-121] under reaction conditions in structures different from the bulk structure which cannot be the geometric base of a realistic picture of the working state. For this part of the challenge we still miss most information as we barely begin to detect these differences qualitatively with very little insight in quantification and formation/ stability kinetics. The combined approach yields information on critical molecular structure elements [122] of the relevant site. All of this knowledge would then have to be incorporated in models dealing with the mesosopic and macroscopic properties [111] of the reaction system comprising formulated catalyst, reactor and reaction conditions. Only then a comparison to experimental data may be used to verify the results from theoretical modelling for the atomistic details of active sites. In this way by treating selective oxidations explicitly as kinetic chains of chains one may further beat the universality concept in heterogeneous catalysts stating that if the adsorption/reaction energy pair of one fragment is defined by the catalyst chemistry (e.g. the activation of di-oxygen) all other reaction sequences are automatically defined and cannot be modified independently [123-125]. Without surpassing this basic concept applying for only one reaction chain, a rational optimization of such difficult reactions as selective oxidations would be barely possible.

\section{On the Electronic Structure of Oxidation Catalysts}

One puzzling aspect in selective oxidation is the dominating influence of the catalyst bulk [126-129] for achieving performance in selective oxygen transfer reactions. Surface-only species such as grafted systems [130-133] are poorly active in selective oxygen transfer but can well combust olefins. When for example vanadia species form the termination layer of bulk reducible oxides such as VPP and M1, they are well capable to transfer oxygen without combusting the substrate. This is realized since long and contributed to the realm of "lattice oxygen" a species that should be absent in catalysts grafted on nonreducible oxides such as alumina or silica.

It is now proposed that the traditional treatment of oxide catalysts as semiconductors can solve [49, 134, 135] this puzzle. The catalysts exhibit then electronic structures determined both by the bulk with valence and conduction bands and by the low dimensional (layer or raft) terminating layers or nanodomains as band gap states. These states lead to the phenomenon of pinning the Fermi level with respect to the top of the valence band. If this quantity shifts then the band gap states move on the energy scale with respect to the Fermi level and change so their occupation with electrons. Now we have to discriminate two cases with respect to the electronic structure of the support. If the support is a non-reducible oxide and no phase formation occurs at the interface, then no charges can be exchanged between support and active phase. Consequently the support is electronically "innocent" and the catalytic properties are given by the structure of the isolated grafted species much in accord to the "site isolation" concept from Table 1 and in agreement with experimental [130, 133] and theoretical treatments [102, 136-138] of the problem. The genesis of active sites for metathesis of propene over grafted $\mathrm{MoO}_{\mathrm{x}}$ catalysts through sacrificial formation of carbene ligands in situ [139] is an illustrative example of the local character of an active site.

The situation gets changed when the terminating vanadia (or other active metal oxide) layer is supported on an oxide with which charge transfer is possible. An extreme case is the self-support of a terminating layer on a defective bulk phase $[140,141]$ of the same nominal structure: then the defects provide the function of exchangeable charge carriers and the following arguments hold also for this situation. A charge imbalance between surface and bulk of the catalyst will result upon formation of a chemically from the bulk different termination layer [142-144] $\left(\mathrm{V}^{5+}\right.$ species e.g.) and/or upon chemisorption of reactants. This imbalance leads to a space charge layer spanning between the charge carrier (e.g. holes in VPP) potentials of the surface and the bulk. The resulting band bending will shift the band gap states with respect to the rigid Fermi level and thus affect the filling of these states with electrons: the system becomes a gas sensor as the electrical conductivity varies with the filling of the band gap states pinned to the Fermi level.

This physical effect that could be used for real sensing purposes has a drastic effect on the catalytic activity. The band bending creates a barrier for transferring electrons via the band gap states (as HOMO of the system) towards oxygen and thus allows controlling in a self-limiting way the availability of activated oxygen. The adsorption of reactants and intermediates at active sites thus directly affects the availability of activated oxygen as electrophilc $\left(\mathrm{O}^{-1}\right)$ or nucleophilic $\left(\mathrm{O}^{-2}\right)$ species and provides the feedback loop required for a dynamical active site that changes its reactivity according to the progress of the chains of elementary steps outlined for example in Figs. 5 and 6. It is obvious that the crystal structure of the support must be stable against geometric modifications from the presence of reactants as otherwise the details of the electronic structure tuning between bulk and terminating layer gets lost and the feedback loop will be opened. This explains the need for intrinsically flexible (non-densely packed) structures of oxides that allow the formation of a 
reactive terminating layer without breakdown of the underlying structure as indicated in the STEM image of Fig. 3b.

This type of selective catalyst phase is thus characterized by two descriptors indicating the formation of a stable terminating layer and the conflicting property of bulk redox stability as stated by the traditional site isolation. The author postulates that these requirements can be realized in a dynamical fashion by formation and re-crystallization of the active phase represented by VPP and in a static fashion by the sophisticated flexibility of polyhedra networks such as in the M1 phase.

The self-limiting action of the feedback loop between adsorbates and oxygen activation explains as a detail the puzzling observation of the inability of selective oxidation catalysts to perform the $\mathrm{CO}$ oxidation reaction. $\mathrm{CO}$ is too weakly bound on high-valent metal ions so that the band bending is insufficient for allowing electrophilic oxygen to be formed; the oxidation catalyst cannot activate weakly bound reactants. This property may further explain how an active site (for example in its fully oxidized from) can activate a specifically bound poorly reactive molecule but may leave untouched an activated form of the substrate interacting too weakly with the site (for example in its reduced form).

The traditional method of determining the conductivity of oxide catalysts [145, 146] for learning about their function finds in combination with in situ measuring absolute quantities of the semiconductor system its modern conceptual verification thanks to the advent [55-57] of the in situ MWPT technique. The function of a working selective oxidation catalyst requires thus the action of local sites with specific reaction capabilities encoded into their geometric structure [147] in combination with the fine tuning of their reactivity by the reacting species through the semiconducting properties of their support phase. This pair of independent descriptors is again a means of breaking the universal scaling relation [124] in selective oxidation. The simultaneous requirement of operation of both descriptors for effective dehydrogenation and for oxygen transfer explains the intricacy of the few well-working catalyst systems and allows rationalizing the failure of single parameter descriptors such as crystal structure motifs $[48,57]$ or of chemical composition of active masses for effective searches of novel catalysts. The discussion presented here may finally serve as explanation why the initial work of Grasselli and Haber based on the ideas of Mars and van Krevelen was essential and necessary for the development of the field. This work in all its relevance also today constitutes one part of the multi-scale phenomenon of selective oxidation; chemical and charge carrier dynamics that were discovered more recently thanks to the availability of in situ analytical methods represent another part. We work now towards unifying these parts into a functional description and into a physics-based kinetic model of selective oxidation.

The author notes that selective oxidation of functionalized organic molecules by molecular and biological catalysts has reached enormous specificities and selectivity with turnover numbers sounding impressive. From such systems we learn much about structural dynamics and the mesoscopic dimensions of controlling interactions. One can expect a potential of such reactions for large-scale applications. This is, however, still far ahead of us now, partly because too little efforts are made between the disjoint communities to collaborate and recognize their respective achievements. The lack of a unified concept of oxidation reactions impedes this collaboration. It is a substantial desire to change this situation for the benefit of approaching the state of a rational design of oxidation processes. Such unification of a catalytic concept can only be achieved if research is conducted jointly between the respective disciplines. This in turn requires first the development of a common language that does not yet exist.

Acknowledgments Open access funding provided by Fritz-HaberInstitute of the Max Planck Society. The author is first indebted to the many co-workers mentioned in the references quoted at FHI Berlin contributing to this endeavour under the longstanding ingenious supervision of A. Trunschke. M. Eichelbaum, M. Hävecker and Th. Lunkenbein contributed invaluably to this work. Many discussions with members (H.J. Freund, J. Sauer) in the Berlin COE UniCat (Unifying Concepts in Catalysis (M. Driess)) provided stimulating input. The Joint Lab BASCAT between TU Berlin, FHI Berlin and the BASF S.E. including extensive cooperation with F. Rosowski is critical for deepening and validating the ideas presented here. The author thanks Bob Grasselli for his paternal input to this work and for providing with his conference series an environment fostering the development of an interdisciplinary understanding of the subject.

Open Access This article is distributed under the terms of the Creative Commons Attribution 4.0 International License (http://crea tivecommons.org/licenses/by/4.0/), which permits unrestricted use, distribution, and reproduction in any medium, provided you give appropriate credit to the original author(s) and the source, provide a link to the Creative Commons license, and indicate if changes were made.

\section{References}

1. Grasselli RK, Tenhover MA (2008) In: Knözinger G, Schüth F, Weitkamp EH (eds) Handbook of heterogeneous catalysis. VCH, Ann Arbor, p 3489

2. Grasselli RK, Burrington JD (1981) Selective oxidation and ammoxidation of propylene by heterogeneous catalysis. Adv Catal 30:133-163

3. Burrington JD, Kartisek CT, Grasselli RK (1980) Aspects of selective oxidation and ammoxidation mechanisms over bismuth molybdate catalysts. II. Allyl alcohol as a probe for the allylic intermediate. J Catal 63:235-254

4. Brazdil JF, Suresh DD, Grasselli RK (1980) Redox kinetics of bismuth molybdate ammoxidation catalysts. J Catal 66:347-367 
5. Burrington JD, Grasselli RK (1979) Aspects of selective oxidation and ammoxidation mechanisms over bismuth molybdate catalysts. J Catal 59:79-99

6. Grasselli RK, Suresh DD (1972) Aspects of structure and activity in uranium-antimony oxide acrylonitrile catalysts. J Catal 25:273-291

7. Mars P, Maessen JGH (1968) Mechanism and kinetics of sulfur dioxide oxidation on catalysts containing vanadium and alkali oxides. J Catal 10:1

8. Mars P, Van Krevelen DW (1954) Chem Eng Sci 3:41

9. Haber J (2009) Fifty years of my romance with vanadium oxide catalysts. Catal Today 142:100-113

10. Haber J, Stoch J, Zazhigalov VA, Bacherikova IV, Cheburakova EV (2008) Selective oxidation of light alkanes on transition metal promoted vanadyl pyrophosphate (VPO) catalysts. Pol J Chem 82:1839-1852

11. Haber J, Turek W (2000) Kinetic studies as a method to differentiate between oxygen species involved in the oxidation of propene. J Catal 190:320-326

12. Haber J, Lalik E (1997) Catalytic properties of $\mathrm{MoO}_{3}$ revisited. Catal Today 33:119-137

13. Trifirò F, Hoser H, Scarle RD (1972) Relationship between structure and activity of mixed oxides as oxidation catalysts: I. Preparation and solid state reactions of Bi-molybdates. J Catal 25:12-24

14. Ertl G (2008) Reactions at surfaces: From atoms to complexity (Nobel lecture). Angewandte Chemie-International Edition 47:3524-3535

15. Ertl G (1990) Elementary steps in heterogenous catalysis. Angewandte Chemie-International Edition in English 29:1219-1227

16. Centi G, Grasselli RK, Trifiro F (1992) Propane ammoxidation to acrylonitrile: an overview. Catal Today 13:661-666

17. Guliants VV, Bhandari R, Brongersma HH, Knoester A, Gaffney AM, Han S (2004) A study of the surface region of the Mo$\mathrm{V}-\mathrm{Te}-\mathrm{O}$ catalysts for propane oxidation to acrylic acid. J Comput Assist 04:634

18. Celaya A, Sanfiz TW, Hansen D, Teschner P, Schnörch F, Girgsdies A, Trunschke R, Schlögl MH, Looi SB (2010) Abd Hamid, dynamics of the MoVTeNb oxide M1 phase in propane oxidation. J Phys Chem C 114:1912-1921

19. Grasselli RK (2002) Fundamental principles of selective heterogeneous oxidation catalysis. Top Catal 21:79-88

20. Girgsdies F, Dong WS, Bartley JK, Hutchings GJ, Schlögl R, Ressler T (2006) The crystal structure of e- $\mathrm{VOPO}_{4}$. Solid State Sci 8:807-812

21. Conte M, Budroni G, Bartley JK, Taylor SH, Carley AF, Schmidt A, Murphy DM, Girgsdies F, Ressler T, Schloegl R, Hutchings GJ (2006) Chemically induced fast solid-state transitions of omega-VOPO4 in vanadium phosphate catalysts. Science 313:1270-1273

22. Dong WS, Bartley JK, Dummer NF, Girgsdies F, Su DS, Schlögl R, Volta JC, Hutchings GJ (2005) Reaction of vanadium phosphates with alcohols at elevated temperature and pressure. J Mater Chem 15:3214-3220

23. Lopez-Sanches JA, Bartley J, Burrows A, Kiely CJ, Hävecker M, Schlögl R, Volta JC, Poliakoff M, Hutchings GJ (2002) Effects of cobalt additive on amorphous vanadium phosphate catalysts prepared using precipitation with supercritical $\mathrm{CO}_{2}$ as an antisolvent. New J Chem 26:1811-1816

24. Hutchings GJ, Lopez-Sanchez JA, Bartley JK, Webster JM, Burrows A, Carley AF, Rhodes C, Hävecker M, Knop-Gericke A, Mayer RW, Schlögl R (2002) Amorphous vanadium phosphate catalysts prepared using precipitation with supercritical $\mathrm{CO}_{2}$ as antisolvent. J Catal 208:197-210

25. Centi G (1993) Vanadyl pyrophosphate-a critical overview. Catal Today 16:5-26
26. Grasselli RK, Suresh DD, Knox K (1970) Crystalline structures of USb3O10 and USbO5 in acrylonitrile catalysts. J Catal 18:356-358

27. Grasselli RK, Callahan JL (1969) Structure-catalytic efficiency relations in uranium-antimony oxide acrylonitrile synthesis catalysts. J Catal 14:93-103

28. Bordes E (2001) Synergistic effects in selective oxidation catalysis: does phase cooperation result in site isolation? Top Catal 15:131-137

29. Han Y-H, Ueda W, Moro-Oka Y (1999) Lattice oxide iontransfer effect demonstrated in the selective oxidation of propene over silica-supported bismuth molybdate catalysts. Appl Catal A 176:11-16

30. Guliants VV, Brongersma HH, Knoester A, Gaffney AM, Han S (2006) Surface active sites present in the orthorhombic M1 phases: Low energy ion scattering study of methanol and allyl alcohol chemisorption over $\mathrm{Mo}-\mathrm{V}-\mathrm{Te}-\mathrm{Nb}-\mathrm{O}$ and $\mathrm{Mo}-\mathrm{V}-\mathrm{O}$ catalysts. Top Catal 38:41-50

31. Celaya A, Sanfiz TW, Hansen A, Sakthivel A, Trunschke R, Schloegl A, Knoester HH, Brongersma MH, Looi SBA (2008) Hamid, How important is the (001) plane of M1 for selective oxidation of propane to acrylic acid? J Catal 258:35-43

32. DeSanto P Jr, Buttrey DJ, Grasselli RK, Lugmair CG, Volpe AF Jr, Toby BH, Vogt T (2004) Structural aspects of the M1 and M2 phases in $\mathrm{MoVNbTeO}$ propane ammoxidation catalysts. Zeitschrift fuer Kristallographie 219:152-165

33. DeSanto P, Buttrey DJ, Grasselli RK, Lugmair CG, Volpe AF, Toby BH, Vogt T (2003) Structural characterization of the orthorhombic phase $\mathrm{M} 1$ in $\mathrm{MoVNbTeO}$ propane ammoxidation catalyst. Top Catal 23:23-38

34. Brazdil JF, Grasselli RK (1983) Relationship between solid state structure and catalytic activity of rare earth and bismuth-containing molybdate ammoxidation catalysts. J Catal 79:104-117

35. Grasselli RK, Burrington JD (1981) Selective oxidation of propylene by heterogeneous catalysis. Chem Indus (Dekker) 5:17-37

36. Pyrz WD, Blom DA, Shiju NR, Guliants VV, Vogt T, Buttrey DJ (2009) The effect of $\mathrm{Nb}$ or Ta substitution into the M1 phase of the $\mathrm{MoV}(\mathrm{Nb}, \mathrm{Ta}) \mathrm{TeO}$ selective oxidation catalyst. Catal Today 142:320-328

37. Pyrz WD, Blom DA, Vogt T, Buttrey DJ (2008) Direct imaging of the MoVTeNbO M1 phase using an aberration-corrected high-resolution scanning transmission electron microscope. Angew Chem Int Ed 47:2788-2791

38. Pyrz WD, Blom DA, Shiju NR, Guliants VV, Vogt T, Buttrey DJ (2008) Using Aberration-corrected STEM imaging to explore chemical and structural variations in the M1 phase of the MoVNbTeO oxidation catalyst. J Phys Chem C 112:10043-10049

39. Blom DA, Li X, Mitra S, Vogt T, Buttrey DJ (2011) STEM HAADF image simulation of the orthorhombic M1 phase in the Mo-V-Nb-Te-O propane oxidation catalyst. Chemcatchem 3:1028-1033

40. Lunkenbein T, Girgsdies F, Wernbacher A, Noack J, Auffermann G, Yasuhara A, Klein-Hoffmann A, Ueda W, Eichelbaum M, Trunschke A, Schlögl R, Willinger MG (2015) Direct imaging of octahedral distortion in a complex molybdenum vanadium mixed oxide. Angew Chem Int Ed 54:6828-6831

41. Blom DA, Vogt T, Allard LF, Buttrey DJ (2014) Observation of sublattice disordering of the catalytic sites in a complex Mo-V$\mathrm{Nb}-\mathrm{Te}-\mathrm{O}$ oxidation catalyst using high temperature STEM imaging. Top Catal 57:1138-1144

42. Li X, Buttrey DJ, Blom DA, Vogt T (2011) Improvement of the structural model for the M1 Phase Mo-V-Nb-Te-O propane (Amm)oxidation catalyst. Top Catal 54:614-626

43. Grasselli RK (2005) Selectivity issues in (amm)oxidation catalysis. Catal Today 99:23-31 
44. Grasselli RK (1999) Advances and future trends in selective oxidation and ammoxidation catalysis. Catal Today 49:141-153

45. Teller RG, Brazdil JF, Grasselli RK, Yelon W (1985) Phase cooperation in oxidation catalysis. Structural studies of the iron antimonate-antimony oxide system. J Chem Soc 81(7):1693-1704

46. Moens L, Ruiz P, Delmon B, Devillers M (1998) Cooperation effects towards partial oxidation of isobutene in multiphasic catalysts based on bismuth pyrostannate. Appl Catal A 171: 131-143

47. Grasselli RK (1985) Selectivity and activity factors in bismuthmolybdate oxidation catalysts. Applied Catalysis 15:127-139

48. Glaum R, Welker-Nieuwoudt C, Dobner CK, Eichelbaum M, Gruchow F, Heine C, Karpov A, Kniep R, Rosowski F, Schlögl R, Schunk SA (2012) Resource-efficient alkane selective oxidation on new crystalline solids: searching for novel catalyst materials. Chem Ing Tech 84(10):1766-1779

49. Eichelbaum M, Hävecker M, Heine C, Rosowski F, Trunschke A, Schlögl R (2015) The electronic factor in alkane oxidation catalysis. Angew Chem Int Ed 54:2922-2926

50. Eichelbaum M, Hävecker M, Heine C, Karpov A, Dobner C-K, Rosowski F, Trunschke A, Schlögl R (2012) The intimate relationship between bulk electronic conductivity and selectivity in the catalytic oxidation of $n$-butane. Angew Chem Int Ed 51:6246-6250

51. Haeggblad R, Wagner JB, Deniau B, Millet J-MM, Holmberg J, Grasselli RK, Hansen S, Andersson A (2008) Substituted Mo$\mathrm{V}(\mathrm{Ti})-\mathrm{Te}(\mathrm{Ce})$-oxide $\mathrm{M} 2$ catalysts for propene ammoxidation. Top Catal 50:52-65

52. Grasselli RK, Lugmair CG, Volpe AF Jr (2008) Doping of MoVNbTeO (M1) and MoVTeO (M2) phases for selective oxidation of propane and propylene to acrylic acid. Top Catal 50:66-73

53. Mestl G, Margitfalvi JL, Vegvari L, Szijjarto GP, Tompos A (2014) Combinatorial design and preparation of transition metal doped MoVTe catalysts for oxidation of propane to acrylic acid. Applied Catalysis a-General 474:3-9

54. Callahan JL, Grasselli RK (1963) A selectivity factor in vaporphase hydrocarbon oxidation catalysis. AIChE J 9:755-760

55. Heine C, Hävecker M, Trunschke A, Schlögl R, Eichelbaum M (2015) The impact of steam on the electronic structure of the selective propane oxidation catalyst MoVTeNb oxide (orthorhombic M1 phase). Phys Chem Chem Phys 17:8983-8993

56. Heine C, Hävecker M, Sanchez-Sanchez M, Trunschke A, Schlögl R, Eichelbaum M (2013) Work function, band bending and microwave conductivity studies on the selective alkane oxidation catalyst MoVTeNb oxide (Orthorhombic M1 Phase) under operation conditions. J Phys Chem C 117:26988-26997

57. Eichelbaum M, Glaum R, Hävecker M, Wittich K, Heine C, Schwarz H, Dobner C-K, Welker-Niewoudt C, Trunschke A, Schlögl R (2013) Towards physical descriptors of active and selective catalysts for the oxidation of $n$-butane to maleic anhydride. ChemCatChem 5:2318-2329

58. Kubicek M, Cai Z, Ma W, Yildiz B, Hutter H, Fleig J (2013) Tensile lattice strain accelerates oxygen surface exchange and diffusion in La1-xSrxCoO3-delta thin films. ACS Nano 7:3276-3286

59. Januschewsky J, Ahrens M, Opitz A, Kubel F, Fleig J (2009) Optimized La0.6Sr0.4CoO3-delta thin-film electrodes with extremely fast oxygen-reduction kinetics. Adv Funct Mater 19:3151-3156

60. Maier J (2012) Building versus structure elements: ionic charge carriers in solids. Zeitschrift Fur Physikalische Chemie 226: 863-870

61. Maier J (2003) Nano-ionics: trivial and non-trivial size effects on ion conduction in solids. Zeitschrift Fur Physikalische Chemie 217:415-436
62. Cimini M, Millet JMM, Ballarini N, Cavani F, Ciardelli C, Ferrari C (2004) Synthesis, characterization and evaluation as catalysts for propane ammoxidation of $\mathrm{VMoSbO}$ systems with rutile-type structure. Catal Today 91-92:259-264

63. Albonetti S, Cavani F, Trifiro F (1996) Key aspects of catalyst design for the selective oxidation of paraffins. Catalysis Reviews: Science and Engineering 38:413-438

64. Celaya A, Sanfiz TW, Hansen F, Girgsdies O, Timpe E, Rödel T, Ressler A, Trunschke R (2008) Schlögl, preparation of phasepure M1 MoVTeNb oxide catalysts by hydrothermal synthesis-influence of reaction parameters on structure and morphology. Top Catal 50:19-32

65. DeSanto P, Buttrey D, Grasselli R, Pyrz W, Lugmair C, Volpe A, Vogt T, Toby B (2006) Comparison of MoVTaTeO and MoVNbTeO M1 crystal chemistry. Top Catal 38:31-40

66. Häggblad R, Wagner JB, Hansen S, Andersson A (2008) Oxidation of methanol to formaldehyde over a series of Fe1-xAlxV-oxide catalysts. J Catal 258:345-355

67. Holmberg J, Hansen S, Grasselli RK, Andersson A (2006) Catalytic effects in propene ammoxidation achieved through substitutions in the M2 phase of the Mo- $\mathrm{V}-\mathrm{Nb}-\mathrm{Te}-$ oxide system. Top Catal 38:17-29

68. Guram A, Hagemeyer A, Lugmair CG, Turner HW, Volpe AF Jr, Weinberg WH, Yaccato K (2004) Application of high throughput screening to heterogeneous liquid and gas phase oxidation catalysis. Adv Syn Catal 346:215-230

69. Wang D, Su DS, Schlögl R (2003) Crystallographic shear defect in molybdenum oxides: structure and TEM of molybdenum sub-oxides $\mathrm{Mo}_{18} \mathrm{O}_{52}$ and $\mathrm{Mo}_{8} \mathrm{O}_{23}$. Cryst Res Technol 38:153-159

70. O'Brien MG, Beale AM, Jacques SD, Buslaps T, Honkimaki V, Weckhuysen BM (2009) On the active oxygen in bulk MoO3 during the anaerobic dehydrogenation of methanol. J Phys Chem C. 113(12):4890-4897

71. Rödel E, Schlögl R, Ressler T (2005) In situ XAS investigation of tungsten as structure directing agent during formation of $\mathrm{Mo}_{5} \mathrm{O}_{14}$ type partial oxidation catalysts. Hasylab Jahresbericht 2005:1105-1106

72. Schlogl R, Knop-Gericke A, Havecker M, Wild U, Frickel D, Ressler T, Jentoft RE, Wienold J, Mestl G, Blume A, Timpe O, Uchida I (2001) In situ analysis of metal-oxide systems used for selective oxidation catalysis: how essential is chemical complexity? Top Catal 15:219-228

73. Ressler T, Timpe O, Neisius T, Find J, Mestl G, Dieterle M, Schlögl R (2000) Time-Resolved XAS investigation of the reduction/oxidation of $\mathrm{MoO}_{3-\mathrm{x}}$. J Catal 191:75-85

74. Rozzi CA, Manghi F, Parmigiani F (2003) Ab initio Fermi surface and conduction-band calculations in oxygen-reduced $\mathrm{MoO}_{3}$. Phys Rev B. 68(7):075106

75. Tokarz-Sobieraj R, Hermann K, Witko M, Blume A, Mestl G, Schlögl R (2001) Properties of oxygen sites at the $\mathrm{MoO}_{3}(010)$ surface: density functional theory cluster studies and photoemission experiments. Surf Sci 489:107-125

76. Radhakrishnan R, Reed C, Oyama ST, Seman M, Kondo JN, Domen K, Ohminami Y, Asakura K (2001) Variability in the structure of supported $\mathrm{MoO}_{3}$ catalysts: Studies using Raman and X-ray absorption spectroscopy with ab initio calculations. J Phys Chem B 105:8519-8530

77. Michalak A, Hermann K, Witko M (1996) Reactive oxygen sites at $\mathrm{MoO} 3$ surfaces: $\mathrm{Ab}$ initio cluster model studies. Surf Sci 366:323-336

78. Volta JC, Tatibouet JM (1985) Structure sensitivity of $\mathrm{MoO}_{3}$ in mild oxidation of propylene. J Catal 93:467-470

79. Dinse A, Schomacker R, Bell AT (2009) The role of lattice oxygen in the oxidative dehydrogenation of ethane on alumina-supported vanadium oxide. Phys Chem Chem Phys 11:6119-6124 
80. Cavani F, Centi G, Trifiro F, Grasselli RK (1988) Dynamic approach to selectivity in heterogeneous partial oxidation. Catal Today 3:185-198

81. Cavani F, Trifirò F (1997) Some aspects that affect the selective oxidation of paraffins. Catal Today 36:431-439

82. Cavani F, Teles JH (2009) Sustainability in catalytic oxidation: an alternative approach or a structural evolution? ChemSusChem. 2(6):508-534

83. Cavani F, Ballarini N, Cericola A (2007) Oxidative dehydrogenation of ethane and propane: how far from commercial implementation? Catal Today 127:113-131

84. Carrero C, Kauer M, Dinse A, Wolfram T, Hamilton N, Trunschke A, Schlögl R, Schomäcker R (2014) High performance $\left(\mathrm{VO}_{\mathrm{x}}\right)_{\mathrm{n}}-\left(\mathrm{TiO}_{\mathrm{x}}\right)_{\mathrm{m}} / \mathrm{SBA}-15$ catalysts for the oxidative dehydrogenation of propane. Catal Sci Technol 4:786-794

85. Beck B, Harth M, Hamilton NG, Carrero C, Uhlrich JJ, Trunschke A, Shaikhutdinov S, Schubert H, Freund H-J, Schlögl R, Sauer J, Schomäcker R (2012) Partial oxidation of ethanol on vanadia catalysts on supporting oxides with different redox properties compared to propane. J Catal 296:120-131

86. Gruene P, Wolfram T, Pelzer K, Schlögl R, Trunschke A (2010) Role of dispersion of vanadia on SBA-15 in the oxidative dehydrogenation of propane. Catal Today 157:137-142

87. Lee EL, Wachs IE (2008) In Situ raman spectroscopy of $\mathrm{SiO}_{2^{-}}$ supported transition metal oxide catalysts: an isotopic 18O-16O exchange study. J Phys Chem C 112:6487-6498

88. Kondratenko EV, Cherian M, Baerns M, Su DS, Schlögl R, Wang X, Wachs IE (2005) Oxidative dehydrogenation of propane over V/MCM-41 catalysts: comparison of $\mathrm{O}_{2}$ and $\mathrm{N}_{2} \mathrm{O}$ as oxidant. J Catal 234:131-142

89. Gao X, Wachs IE (2002) Molecular engineering of supported vanadium oxide catalysts through support modification. Top Catal 18:243-250

90. Kondratenko EV, Cherian M, Baerns M, Su D, Schlögl R, Wang $X$, Wachs IE (2005) Oxidative dehydrogenation of propane over V/MCM-41 catalysts: comparison of $\mathrm{O}_{2}$ and $\mathrm{N}_{2} \mathrm{O}$ as oxidants. J Catal 234:131-142

91. Wachs IE, Jehng JM, Ueda W (2005) Determination of the chemical nature of active surface sites present on bulk mixed metal oxide catalysts. J Phys Chem B 109(6):2275-2284

92. Kampe P, Giebeler L, Samuelis D, Kunert J, Drochner A, Haass F, Adams AH, Ott J, Endres S, Schimanke G, Buhrmester T, Martin M, Fuess H, Vogel H (2007) Heterogeneously catalysed partial oxidation of acrolein to acrylic acid-structure, function and dynamics of the V-Mo-W mixed oxides. Phys Chem Chem Phys 9:3577-3589

93. Fushimi R, Shekhtman SO, Gaffney A, Han S, Yablonsky GS, Gleaves JT (2005) TAP vacuum pulse-response and normalpressure studies of propane oxidation over $\mathrm{MoVTeNbO}$ oxide catalysts. Ind Eng Chem Res 44:6310-6319

94. Grasselli RK, Buttrey DJ, Burrington JD, Andersson A, Holmberg J, Ueda W, Kubo J, Lugmair CG, Volpe AF Jr (2006) Active centers, catalytic behavior, symbiosis and redox properties of $\mathrm{MoV}(\mathrm{Nb}, \mathrm{Ta}) \mathrm{TeO}$ ammoxidation catalysts. Top Catal 38:7-16

95. Schlögl R (2015) Heterogeneous Catalysis. Angew Chem Int Ed 54:3465-3520

96. Alnoncourt RN, Csepei LI, Hävecker M, Girgsdies F, Schuster ME, Schlögl R, Trunschke A (2014) The reaction network in propane oxidation over phase-pure MoVTeNb M1 oxide catalysts. J Catal 311:369-385

97. Sadakane M, Ueda W (2012) Building block synthesis of crystalline Mo-V-based oxides: selective oxidation catalysts. J Jpn Petrol Inst 55:229-235

98. Ueda W, Sadakane M, Ogihara H (2008) Nano-structuring of complex metal oxides for catalytic oxidation. Catal Today $132: 2-8$
99. Amakawa K, Kolenko YV, Villa A, Schuster ME, Csepei LI, Weinberg G, Wrabetz S, Naumann d'Alnoncourt R, Girgsdies F, Prati L, Schlögl R (2013) Multifunctionality of crystalline MoV $(\mathrm{TeNb}) \mathrm{M} 1$ oxide catalysts in selective oxidation of propane and benzyl alcohol. ACS Catal 3(6):1103-1113

100. Alnoncourt R, Kolen'ko YV, Schlogl R, Trunschke A (2012) A new way of probing reaction networks: analyzing multidimensional parameter space. Comb Chem Hight Screen 15(2):161-169

101. Hess C, Schlögl R (2011) Nanostructured catalysts: selective oxidation. The Royal Chemical Society, Cambridge

102. Liu J, Mohamed F, Sauer J (2014) Selective oxidation of propene by vanadium oxide monomers supported on silica. J Catal 317:75-82

103. Keranen J, Guimon C, Auroux A, Iiskola EI, Niinisto L (2003) Gas-phase synthesis, structure and surface acid-base properties of highly dispersed vanadia/titania/silica catalysts. Phys Chem Chem Phys 5:5333-5342

104. Védrine JC (2002) The role of redox acid-base and collective properties and of cristalline state of heterogeneous catalysts in the selective oxidation of hydrocarbons. Top Catal 21:97-106

105. Vedrine JC, Millet JMM, Volta J-C (1996) Molecular description of active sites in oxidation reactions: acid-base and redox properties, and role of water. Catal Today 32:115-123

106. Desikan AN, Zhang WM, Oyama ST (1995) The effect of acidbase properties of supported molybdenum oxide in propylene oxidation. J Catal 157:740-748

107. Blasco T, Lopez Nieto JM, Dejoz A, Vazquez MI (1995) Influence of the acid-base character of supported vanadium catalysts on their catalytic properties for the oxidative dehydrogenation of $n$-butane. J Catal 157:271-282

108. Ai M, Ikawa T (1975) The acid-base properties of MoO3$\mathrm{Bi} 2 \mathrm{O} 3-\mathrm{P} 2 \mathrm{O} 5$ catalysts and their correlation with catalytic activity and selectivity. J Catal 40:203-211

109. Metiu H, Chretien S, Hu ZP, Li B, Sun XY (2012) Chemistry of Lewis acid-base pairs on oxide surfaces. J Phys Chem C 116:10439-10450

110. Prasad V, Karim AM, Arya A, Vlachos DG (2009) Assessment of overall rate expressions and Multiscale, Microkinetic model uniqueness via experimental data injection: ammonia decomposition on Ru/gamma-Al2O3 for hydrogen production. Ind Eng Chem Res 48:5255-5265

111. Geske M, Korup O, Horn R (2013) Resolving kinetics and dynamics of a catalytic reaction inside a fixed bed reactor by combined kinetic and spectroscopic profiling. Catal Sci Technol 3:169-175

112. Baddour-Hadjean R, Smirnov MB, Smirnov KS, Kazimirov VY, Gallardo-Amores JM, Amador U, Arroyo-de Dompablo ME, Pereira-Ramos JP (2012) Lattice dynamics of beta-V2O5: Raman spectroscopic insight into the atomistic structure of a high-pressure vanadium pentoxide polymorph. Inorg Chem 51:3194-3201

113. Sanfiz AC, Hansen TW, Teschner D, Schnorch P, Girgsdies F, Trunschke A, Schlögl R, Looi MH, Hamid SBA (2010) Dynamics of the MoVTeNb oxide M1 phase in propane oxidation. J Phys Chem C 114:1912-1921

114. Leone SR, Ahmed M, Wilson KR (2010) Chemical dynamics, molecular energetics, and kinetics at the synchrotron. Phys Chem Chem Phys 12:6564-6578

115. Ovsitser O, Cherian M, Brückner A, Kondratenko EV (2009) Dynamics of redox behavior of nano-sized VOx species over TiSi-MCM-41 from time-resolved in situ UV/Vis analysis. J Catal 265:8-18

116. Frank B, Fortrie R, Hess C, Schlögl R, Schomäcker R (2009) Reoxidation dynamics of highly dispersed $\mathrm{VO}_{\mathrm{x}}$ species supported on $\gamma$-alumina Appl. Catal. A: General 353:288-295 
117. Salehoun V, Khodadadi A, Mortazavi Y, Talebizadeh A (2008) Dynamics of $\mathrm{Mn} / \mathrm{Na} 2 \mathrm{WO} / \mathrm{SiO} 2$ catalyst in oxidative coupling of methane. Chem Eng Sci 63:4910-4916

118. Launay H, Loridant S, Pigamo A, Dubois JL, Millet JMM (2007) Vanadium species in new catalysts for the selective oxidation of methane to formaldehyde: specificity and molecular structure dynamics with water. J Catal 246:390-398

119. Wagner JB, Timpe O, Hamid FA, Trunschke A, Su DS, Widi RK, Abd SB, Hamid A, Schlögl R (2006) Controlling the dynamics of selective oxidation catalysts: surface texturing of $\mathrm{MoVNbTeO}$. Chem Commun 38:51-58

120. Hävecker M, Knop-Gericke A, Schlögl R (2004) X-ray sight active sites: dynamics of catalytic surfaces under reaction conditions. BESSY Highlights 2005:10-11

121. Topsøe H, Ovesen CV, Clausen BS, Topsøe NY, Nielsen PH, Törnqvist E, Nørskov JK (1997) Importance of dynamics in real catalyst systems. Stud Surf Sci Catal 109:121-139

122. Manganas D, Kristiansen P, Duda L-C, Knop-Gericke A, DeBeer S, Schlögl R, Neese F (2014) Combined experimental and $\mathrm{Ab}$ Initio multireference configuration interaction study of the resonant Inelastic X-ray scattering spectrum of $\mathrm{CO}_{2}$. J Phys Chem C 118:20163-20175

123. Wang SG, Temel B, Shen JA, Jones G, Grabow LC, Studt F, Bligaard T, Abild-Pedersen F, Christensen CH, Norskov JK (2011) Universal bronsted-evans-polanyi relations for $\mathrm{C}-\mathrm{C}-\mathrm{C}-$ $\mathrm{O}, \mathrm{C}-\mathrm{N}, \mathrm{N}-\mathrm{O}, \mathrm{N}-\mathrm{N}$, and $\mathrm{O}-\mathrm{O}$ dissociation reactions. Catal Lett 141:370-373

124. Wang S, Petzold V, Tripkovic V, Kleis J, Howalt JG, Skulason E, Fernandez EM, Hvolbaek B, Jones G, Toftelund A, Falsig H, Bjorketun M, Studt F, Abild-Pedersen F, Rossmeisl J, Norskov JK, Bligaard T (2011) Universal transition state scaling relations for (de)hydrogenation over transition metals. Phys Chem Chem Phys 13:20760-20765

125. Vojvodic A, Calle-Vallejo F, Guo W, Wang S, Toftelund A, Studt F, Martinez JI, Shen J, Man IC, Rossmeisl J, Bligaard T (2011) On the behavior of Brønsted-Evans-Polanyi relations for transition metal oxides. J Chem Phys 134(24):244509

126. Zhao C, Wachs IE (2008) Selective oxidation of propylene over model supported $\mathrm{V}_{2} \mathrm{O}_{5}$ catalysts: influence of surface vanadia coverage and oxide support. J Catal 257:181-189

127. Routray K, Briand LE, Wachs IE (2008) Is there a relationship between the MO bond length (strength) of bulk mixed metal oxides and their catalytic activity? J Catal 256:145-153

128. Lee EL, Wachs IE (2008) Surface chemistry and reactivity of well-defined multilayered supported $\mathrm{M} 1 \mathrm{Ox} / \mathrm{M} 2 \mathrm{Ox} / \mathrm{SiO}_{2}$ catalysts. J Catal 258:103-110

129. Kulkarni D, Wachs IE (2002) Isopropanol oxidation by pure metal oxide catalysts: number of active surface sites and turnover frequencies. Appl Catal A 237:121-137

130. Yang S, Iglesia E, Bell AT (2006) Nature, density, and catalytic role of exposed species on dispersed $\mathrm{VOx} / \mathrm{CrOx} / \mathrm{A} 12 \mathrm{O} 3$ catalysts. J Phys Chem B 110:2732-2739

131. Yang S, Iglesia E, Bell AT (2005) Oxidative dehydrogenation of propane over V2O5/MoO3/Al2O3 and V2O5/Cr2O3/A12O3: structural characterization and catalytic function. J Phys Chem B 109:8987-9000

132. Dai H, Bell AT, Iglesia E (2004) Effects of molybdena on the catalytic properties of vanadia domains supported on alumina for oxidative dehydrogenation of propane. J Catal 221:491-499
133. Chen K, Bell AT, Iglesia E (2002) The relationship between the electronic and redox properties of dispersed metal oxides and their turnover rates in oxidative dehydrogenation reactions. J Catal 209:35-42

134. Maier J (2009) Nanoionics: ionic charge carriers in small systems. Phys Chem Chem Phys 11:3011-3022

135. Maier J (2009) Thermodynamics of nanosystems with a special view to charge carriers. Adv Mater 21:2571-2585

136. Brazdova V, Ganduglia-Pirovano MV, Sauer J (2010) Vanadia aggregates on an ultrathin aluminum oxide film on $\mathrm{NiAl}(110)$. J Phys Chem C 114:4983-4994

137. Todorova TK, Doebler J, Sierka M, Sauer J (2009) Vanadium oxides supported on a thin silica film grown on $\operatorname{Mo}(112)$ : insights from density functional theory. J Phys Chem C 113:8336-8342

138. Rozanska X, Fortrie R, Sauer J (2007) Oxidative dehydrogenation of propane by monomeric vanadium oxide sites on silica support. J Phys Chem C 111:6041-6050

139. Amakawa K, Wrabetz S, Krohnert J, Tzolova-Muller G, Schlögl $\mathrm{R}$, Trunschke A (2012) In Situ generation of active sites in olefin metathesis. J Am Chem Soc 134:11462-11473

140. Jiang L, Wende T, Claes P, Bhattacharyya S, Sierka M, Meijer G, Lievens P, Sauer J, Asmis KR (2011) Electron distribution in partially reduced mixed metal oxide systems: infrared spectroscopy of CemVnOo + gas-phase clusters. J Phys Chem A 115:11187-11192

141. Ganduglia-Pirovano MV, Hofmann A, Sauer J (2007) Oxygen vacancies in transition metal and rare earth oxides: current state of understanding and remaining challenges. Surf Sci Rep 62:219-270

142. Merzlikin SV, Tolkachev NN, Briand LE, Strunskus T, Woll C, Wachs IE, Grunert W (2010) Anomalous surface compositions of stoichiometric mixed oxide compounds. Angewandte Chemie Inte Edn 49:8037-8041

143. Heine C, Hävecker M, Stotz E, Rosowski F, Knop-Gericke A, Trunschke A, Eichelbaum M, Schlögl R (2014) Ambient-pressure soft $\mathrm{x}$-ray absorption spectroscopy of a catalyst surface in action: closing the pressure gap in the selective n-butane oxidation over vanadyl pyrophosphate. J Phys Chem C 118:20405-20412

144. Hävecker M, Wrabetz S, Kröhnert J, Naumann d'Alnoncourt R, Kolen'ko YV, Girgsdies F, Schlögl R, Trunschke A (2012) Surface chemistry of phase-pure M1 MoVTeNb oxide during operation in selective oxidation of propane to acrylic acid. J Catal 285:48-60

145. Millet JMM, Marcu IC, Herrmann JM (2005) Study by electrical conductivity measurement of redox properties of vanadium antimonate and mixed vanadium and iron antimonate. $\mathrm{J}$ Mol Catal A: Chem 226:111-117

146. Herrmann JM (1994) Electrical conductivity characterization of Eurocat titania-supported vanadia catalysts. Catal Today 20(1):135-152

147. Amakawa K, Sun LL, Guo CS, Havecker M, Kube P, Wachs IE, Lwin S, Frenkel AI, Patlolla A, Hermann K, Schlögl R, Trunschke A (2013) How strain affects the reactivity of surface metal oxide catalysts. Angewandte Chemie Inter Edn 52:13553-13557 